\title{
Laboratory markers as predictors of the outcome of resuscitation; a pilot study
}

\author{
EC Reynolds \\ From International Conference for Healthcare and Medical Students 2011 \\ Dublin, Ireland. 4-5 November 2011
}

\section{Introduction}

Deciding when not to attempt resuscitation (DNAR) is problematic for many reasons but not least because of the difficulty in predicting the outcome in any given individual. "Futility" is often used as a justification for DNAR, but it lacks precision and is prone to subjectivity. Predictive scoring systems might avoid unnecessary pessimism and also minimise truly futile attempts which are distressing and undignified. Existing scores have a high specificity and low sensitivity, and may have useful negative predictive value but they are based on trials involving fewer than 200 patients. Sepsis and renal impairment appear to indicate a poor outcome but no studies have examined biochemical indicators of infection and inflammation (elevated $\mathrm{C}$ reactive protein (CRP) or white cell counts (WCC)). This feasibility study examined the relationship between elevated CRP, WCC, and creatinine and poor outcome of CPR.

\section{Methods}

The study was performed retrospectively on information submitted to the national resuscitation audit database on CPRs between July 1st and Dec 31st 2010 in a large UK teaching hospital. Creatinine, CRP and WCC values up to 72 hours pre-arrest were analyzed. The study covered only ward-based arrests and excluded emergency department, intensive and coronary care units.

\section{Results}

Data for 56 arrests were available in the study period. 8 patients survived to discharge $(14.3 \%)$ and of the 48 who died (85.8\%), 36 failed initial CPR, 8 died within 24 hours, and 4 died later in hospital. Data are presented as median values with ranges.
Table 1 Data for 56 arrests

\begin{tabular}{lcl}
\hline Numbers & $\begin{array}{l}\text { Survivors }=\mathbf{8} \\
\mathbf{( 1 4 . 2 \% )}\end{array}$ & $\begin{array}{l}\text { Non-survivors = 48 } \\
\mathbf{( 8 5 . 8 \% )}\end{array}$ \\
\hline Age (years) & $77.5(48-94)$ & $79.5(35-98)$ \\
CRP $(\mathrm{mg} / \mathrm{L})$ & $50.7(2.6-147.7)$ & $48.1(2.4-278.3)$ \\
WCC $(\times 109 / \mathrm{L})$ & $9.0(4.1-19.3)$ & $10.75(4.2-18.3)$ \\
Creatinine $(\mathrm{mmol} / \mathrm{L})$ & $80.0(26-193)$ & $106(26-677)$ \\
\hline
\end{tabular}

Only 4 out of the 56 undergoing CPR had a CRP of less than 10 .

\section{Conclusions}

There was no correlation between age, creatinine, CRP, or WCC on the outcome of CPR suggesting these should not be major factors influencing DNAR decisions. However this study only involved small numbers and was a feasibility study for a larger analysis of around $1500 \mathrm{CPR}$ attempts which will aim to construct and later validate a predictive scoring system.

Published: 9 July 2012

doi:10.1186/1753-6561-6-S4-029

Cite this article as: Reynolds: Laboratory markers as predictors of the outcome of resuscitation; a pilot study. BMC Proceedings 2012 6(Suppl 4): O29.

University of Bristol, UK

(c) 2012 Reynolds; licensee BioMed Central Ltd. This is an Open Access article distributed under the terms of the Creative Commons 